importance in this direction, but because they lie a little out of the beaten track of medical men, they do not get the attention they deserve; I may add the admirable address of the President, in the Mechanical section of the British Association, delivered in August, 1875, at Bristol, on "stream lines." Of these, as being the common property of all scientific men, whether medical or others, I shall not hesitate to avail myself to-day. My proposal is, to go through one or two hydrostatic and hydraulic laws, upon which certain functions of the body connected with the circulation, and probably also with respiration, are founded. And first I hope to show you, by experimental demonstration, the laws which are involved. Where are we to look for these laws? For there are several regions, more than perhaps some of you may at first think, where physics is conterminous with medicine. In the questions which we, as medical men, have to consider, these are mainly three. First, the flowing of fluids through pipes and orifices; secondly, the laws of motion as influencing these; and thirdly, the acoustical results both in incompressible and in elastic fluids. I propose to speak first of incompressible fluids in two forms; as they flow through orifices, and as they pass through capillary tubes.

In 1644, Torricelli made a series of observations (following others by Castelli), tending to show that the discharge of water through orifices varied as the square root of the head or charge.

Now the head or charge may be simply described as the height of the surface of the water from the orifice through which it flows. If the vessel be constantly filled with water up to that level and allowed to discharge by the orifice, omitting friction (which is, however, an important factor), it can be proved that the velocity of efflux is that of a body falling through a height equal to that of the level above the orifice. The velocity may be represented by

$$
V=\sqrt{2 \mathrm{~g} \mathrm{~h}}
$$

This old familiar equation of falling bodies in many respects is of great value. But when you come to measure experimentally on this plan by gauging the cross section of the orifice (taking the square of the diameter into $\frac{\pi}{4}$ as representing a circular area) and the outflow of the fluid during a given time, you ought to get the equation of falling bodies. But no such thing occurs. You can hardly refer this difference to friction. The friction round a small thin finear orifice is extremely small, but the actual outflow is only 0.62 of what is calculated by Torricelli's theory, about $\frac{3}{5}$. That is all the water that comes out. Now, so far from this causing a difficulty, or reflecting in any way upon the mathematical demonstration, it has been thoroughly explained; and so simple is the explanation that it surprises one that engineers and other practical men should never have struck upon it sooner. All the water is tending downwards by the force of gravity, and it all desires to get out, but the particles are disposed differently at the edge of the orifice; some are only just sliding along the walls; nearly all the mass is more or less oblique to the axis of the orifice. What is the result? Just what should happen. The water as it comes out, carrying on the momentum it received inside, forms a curved surface, the narrowest point of which is much smaller than the orifice itself. It is this hustling and jostling of the particles which produces the effect termed the vena contracta. When once this fact is recognised, the only thing is to measure and allow for it. I have the proportions as estimated by French engineers, who have worked it out better than any Englishman with the one exception of that many-sided man Sir William Thomson. The general result of observation is that this vena contracta, where the streams meet and obstruct the coming out, occurs at about the radius of the orifice from and beyond it, and that, if the orifice be circular, it measures 0.79 of its diameter, the area of which is equal to $(0 \cdot 79)^{2}$, or 6241 .

There are also two other curious phenomena, which have engaged the attention of Poncelet and Savart. As the water comes out it closes in and becomes smaller; but soon after it has got past the orifice a rotatory motion takes place. It also begins to oscillate in a direct line, and in a sense to become like a wave, insomuch that the column breaks up. The impulse seems to act and react; there is a conversion of the first calm transparent part, like a stem of crystal, into a second, agitated, more or less opaque, so far possessed of regular form that it can be seen to be divided into a certain number of elongated swellings, of which the maximum diameter is greater than the orifice, separated by narrower portions. The cause of this rotation is not yet explained. There have been, indeed, feeble attempts at explanation, the resistance of the air, the resistance of the fluid, or its viscosity. I propose to show you, in the first instance, the vena contracta; secondly, the longitudinal vibration which always occurs when fluids flow through an abruptly constricted orifice; and lastly, the rotation or in version as it has been termed. [It was shoun that the water is contracted by its oun velocity cabout the diameter of the orifice; that it becomes discontinuous, setting up a vibratory motion in the column as it comes out ; and that it rotates.] The efflux with a linear orifice is only 62 per cent." of the quantity which ought normally to come out of the area of the orifice, but it can be very much altered by nozzleswhat the French call ajutages. If you put a cylindrical tube into the hole, so as to diminish the jostling by carrying the fluid in a parallel line, it raises the amount to 82 per cent. if you take a truncated cone it raises it to 92 per cent.; if you take a truncated cone inverted with its smaller end directed towards the cistern, a very curious result occurs; instead of raising the efflux to 100 , it does a great deal better-it gives 125 . The cone outside throws backwards the reciprocal action of the fluid particles inside. Your nozzle becomes, as it were, the vena contracta, moulding within the cistern an imaginary cone, which enables the orifice to deliver a much larger efflux than according to the orjginal calculation.

Now, it is to the action of this vena contracta, and to the rotation and vibration which seem to be its constant concomitants, that nearly all the fluid murmurs and thrills which occur in the human body must be referred. I believe that wherever an obstacle is placed in the way of a current of air, vibration occurs; to this canse I refer the respiratory murmurs heard in the lungs; but, without even going so far, there can be no doubt that cardiac murmurs, murmurs in incompressible fluid, depend to a very large extent upon vihration in the current of blood. In both cases a back eddy, a vena contracta occurs, and in that vena contracta there is vibration.

\section{REMARKS ON LITHOTRITY AT ONE SITTING.}

BY WILLIAM CADGE, F.R.C.S.,

SENIOR SURGEON TO THE NORFOUK AND NORWICH HOSPYTAL.

WHEN I first became aware of the views of Prof. Bigelow on the treatment of stone in the bladder by rapid lithotrity and large instruments, I confess that they seemed to me crude in theory and likely to lead to dangerous results in practice. A more careful examination of the subject and a perusal of his excellent paper have induced me to modify my first impressions, and to think that in the new method it may be found that we possess, not only a novelty, but a real advance in practical lithotrity.

In common with all English lithotritists, it has hitherto been my habit, at the first sitting, to do but little with the instrument (not knowing what the tolerance of the bladder would be), and at subsequent sittings to act more freely. I have, of course, met with cases, though they are rare, in which one sitting has sufficed to bring about a cure; more frequently there have been five or six, sometimes ten or twelve, and occasionally fifteen or even twenty sittings,depending in great measure on the size of the stone and the power of the patient to void the débris. In old persons with a weak bladder and enlarged prostate $I$ have generally introduced the lithotrite two, three, or four times at a sitting and in some cases of chronic retention of urine combined with calculus it has been necessary to remove as well as crush the whole of the stone. In doing this I have sometimes used Clover's syringe, but more frequently have trusted to the quicker and less disturbing action of the scoop lithotrite.

Speaking generally, the chief principles of English lithotrity, as taught by Brodie and subsequent writers, are-1, 
to do as little as possible with instruments, especially at the first sitting, leaving the extrusion of the fragments as much as possible to natural efforts; and 2, to use small rather than large instruments. Bigelow's method, as a leader-writer in The LANCET has said, 1 is based on opposite and contradictory principles. He proposes-1, to do as much as possible at the first sitting, and, in all but very large stones, thoroughly and at once to clear the bladder; 2 , to use the largest instruments for this purpose which the urethra will allow. Both these propositions are new to English lithotrity. He argues that the average bladder and urethra are not extremely susceptible, and that more harm is done by leaving sharp angular fragments to worry the mucous membrane than by the prolonged use of smooth-polished instruments in removing them. In evidence of this tolerance of the bladder, he refers to the generally favourable results of lithotrity; to the success in the treatment of urethral stricture by forcible dilatation and laceration; and to the quick recovery of the bladder from the bruising and injury inflicted during the removal, by lithotomy, of large or rough stones.

The use of large instruments in crushing the stone, and especially in evacuating the fragments, is quite as great an innovation as the principle of the comparative harmlessness of long sittings. I have hitherto felt that large instruments, whether for crushing or evacuating, are more apt to produce rigors, fever, and cystitis than small ones, and it is probable that this view is correct when ether is not used. With full anæsthesia, however, Bigelow maintains and has found that no harm comes of using instruments equal in size to about 16 to 20 English scale, and it is certain that, without these large evacuating catheters, lithotrity at one sitting on his plan will not be practicable for full-sized stones.

The question then for solution is, Which principle is correct and most generally applicable-short first sittings and instruments of moderate size, or thorough clearance of the bladder at one sitting by means of large evacuating tubes? I do not now propose to give any decided opinion. time and experience can alone decide the question, and as a contribution helping to this end I wish briefly to report a few cases in which I have recently adopted Bigelow's method.

CASE 1.-F. R-, aged thirty-one. Stone of about two years' growth; it measured an inch and a half in one, and an inch in another diameter. Urine and bladder healthy; can retain water from one to two hours.-February 27 th Under full etherisation, I removed the whole stone at one sitting, using two of my orelinary unfenestrated lithotrites by turns, and a No. 16 evacuating catheter. The lithotrites were used alternately nine or ten times, and the evacuating tube twice. The time occupied was about half an hour. The quantity of lithic-acid stone weighed, when dried, 240 grains, of which 180 grains were removed by the tube and 60 by the lithotrites. Scarcely any bleeding accompanied the proceeding. I took care, as I always do, to keep the patient covered, both body and limbs, with thick flannel during the operation, and at the conclusion a half-grain morphia suppository was placed in the rectum. No rigor or trouble of any kind followed; he passed a few fragments the next day which had escaped detection, and on the fourth day he had lumbar pain and a rise in temperature, which subsided on the fifth day, when he voided an entirely fresh stone, which had probably just escaped from the kidney or ureter. In a few days more he was quite well.

CAsE 2.-J. R_- aged sixty-one, a stout, heavy man, with an irritable bladder, so irritable that $I$ had almost resolved on lithotomy, although the stone was not large, but the success of the previous case encouraged me to repeat the experiment.-March 2nd : Under ether, and in a quarter of an hour, I removed the whole of a stone, which measured about an inch. The same instruments were used. The lithotrites were introduced five or six times, and the evacuating tube twice. The dried fragments of stone which were saved weighed 80 grains, of which 52 were removed by the lithotrites, and 28 by the catheter. The patient had no bad symptoms; he voided no more stone; got up and walked about the next day, and was quite well in a day or two more.

CASE 3.-Mr. D__, aged sixty-six, a farmer from Suffolk, a very nervous timid man, grey-haired, but stont. His father died after lithotrity many years ago, and several members of his family are subject to stone or gravel. His urine is healthy, but his bladder is very irritable, and he micturates with great pain every hour or hour and a half. On first sounding, without ether, the stone appeared to be of a magnitude to require lithotomy. He could not, however, bear the full use of instruments. On March 12th I therefore gave him ether, in order to measure the size of the stone accurately. Finding it not exceeding an inch and a half, it was at once crushed and removed, as in the other cases. The lithotrites were used six or eight times, and the evacuating catheter thrice, after which I could detect no fragment with a sound or lithotrite. The sitting lasted about half an hour. The stone was lithic acid, with a thin covering of phosphates, and weighed 133 grains when dried, of which forty where removed by the lithotrites and ninety-three by the catheter. There was rather more bleeding than in the other cases. A morphia suppository was used, and he was ordered chiefly a milk diet. Retention of urine followed, which required the catheter every three or four hours for a few days. He was feverish, and had slight cystitis and considerable pain about the root of the penis. About a week after he again took ether, and a few small fragments were crushed and removed with the lithotrite alone. This was not followed by retention, and his bladder was easier, but for some time he continued to experience bladder irritation and urethral pain during micturition.

CAsE 4.-Mr. C-, aged seventy-four, a large rubicund gentleman, with two or three small stones, and increasing vesical irritability. He has long suffered from lithic gravel and small stones, but of late, owing, as he thought, to the use of rain water, no gravel has been passed. It was rather that as his age increased so did his prostate gland; the outflow of urine became somewhat impeded, and calculi, which used to escape easily, were now detained in the bladder. On March 13th, under ether, and in about ten minutes, two or three small uric-acid stones were broken and removed by the same instruments as in the former cases, in all thirty grains; but in this, as in the other cases, there was a considerable amount of fine sand and pulverised stone, which was lost. A little cystitis followed, but in a week's time he was well.

CASE 5.-Mr. W_- aged sixty-one, a large robust man, with a small stone and symptoms of moderate severity.March 20th: Under ether, and in a few minutes, the bladder was cleared of a lithic stone which weighed between twenty and thirty grains. In this case the orifice of the urethra was small, and required to be slit up for half an inch in order to extricate the lithotrite filled with stone, and to allow No. 14 evacuating catheter to enter. He had no trouble afterwards, and was well in a few days.

In these cases I used only the ordinary unfenestrated lithotrites, and the smallest of Bigelow's catheters. It was easy to recomise the advantage of the full-sized evacuating catheter, and to see that the larger the catheter the greater will be the rapidity and facility in removing fragments. Further experience will, perhaps, enable me to overcome the prejudice against these large instruments, and at the same time to manipulate them more deftly; in the meantime, I think the new plan should not be attempted by anyone who has not already acquired by plentiful experience on the living, and by repeated experiment on the dead body, all the little knacks and tricks which go far to make up successful lithotrity.

The behaviour of the bladder towards a stone in it is most peculiar and puzzling. In one case it displays almost perfect indifference, and even acts the part of host with an approach to hospitality, and allows the guest to stay and grow until it reaches enormous proportions. Some years ago I made a post-mortem examination on an old man dead of abdominal aortic aneurism, and discovered accidentally that the bladder contained a large lithic stone which weighed nearly nine ounces. The bladder was healthy, and the mucous membrane pale. For years I had occasionally attended this patient, but so little did this large stone trouble him that neither he nor I was aware of its presence In other cases, no sooner does a stone enter at one portal than the conflict begins, and goes on until either it is turned out along the urethral passage at the other portal, or the bladder is perpetually fretted, worried, and inflamed until either the surgeon or death comes to end the dispute. So it is under lithotrity; it is impossible, or nearly so, to predict when inflammation and trouble will follow a sitting. Oftentimes it comes on when the stone is small, the patient healthy, and the manipulations have been most gentle and easy. In 
other cases the roughest handling under adverse circumstances is borne with impunity. It is this uncertainty which has hitherto made me careful to do but little at the first sitting. But it may be that the boldest course is the safest; and it must be admitted that when cystitis does follow the first sitting, it is a comfort to feel that by the new method there are no sharp fragments to perpetuate the irritation and retard recovery. Cases such as these I have reported, and a study of those related by Bigelow, will go some way to win a place for this new method in English practice. What that place may be-whether it will extend the limits of lithotrity, and, if so, to what extent; what modifications of it and improvements in it are possible,--these are points which further experience will decide. In the meantime I cannot forbear expressing my high appreciation of the work which Professor Bigelow has already accomplished, and of the fair, candid, and forcibly written essay in which he has advocated his views.

Norwich.

\section{NOTES ON UNUSUAL OR RARE FORMS OF SKIN DISEASE.}

By TILBURY FOX, M.D., F.R.C.P.,

PHYSICIAN TO THE DEPARTMENT FOR SKIN DISEASES IN UNIVERSITY COLLEGE HOSPITAL.

\section{III.-CASE OF ACNE CACHECTICORUM.}

EDMUND T. C_- a , aged fifty-three years, unmarried, and a "ne'er-do-well," who had become broken in circumstances and a wanderer, consulted me in 1877 for an acneiform eruption studding the greater part of his skin. $\mathrm{He}$ was under the impression that he had syphilis when thirty years old, and had a chancre on the outside of the penis. He was certainly treated with mercury, but never had an eruption. He showed no sign of syphilis at this date (1877), and was not scrofulous. After four years spent in America in search of a living, during which time he endured great privations and lived very badly, sometimes not tasting meat for a month, and living to a great extent on brandy-and-water and tea, he returned to England in 1873, and then first noticed some spots on his legs, for which he consulted a medical man. Probably the patient was looking very cachectic, for he was told he wanted potash in his blood, and was directed to take plenty of well-cooked vegetables and meat. He then lived under slightly better conditions for two months, and badly again for fifteen months. The spots were not very much noted at this time, but still confined to the legs. In March, 1875, in consequence of coming into possession of a little money, he stopped at the seaside for five weeks, and indulged in various excesses. Here he grew worse in health, fresh crops of spots came out, and for the first time a few on the back of the forearm, and the old spots became inflamed. $0 \mathrm{n}$ his return to London his doctor diagnosed secondary syphilis, and treated him accordingly for three months, but without benefit. The eruption continuing, he attended a hospital for three months in the summer of 1876. Subsequently he took a series of Turkish baths, and in April, 1877, he applied for treatment at University College Hospital. At that time his legs, from the groin downwards to the ankle, and the arms to just above the elbow, were dotted over pretty thickly with very indolent unmistakable acne spots having a hard livid base and a slight purulent cap in many cases. They were most numerously situated on the front of the thigh and back of the leg, and on the external aspect of the arms. There were none on the trunk nor on the face. The patient was put upon cod-liver oil and a mixture of dilute nitro-hydrochloric acid and perchloride of iron, and at once commenced to mend. Circumstances enabled him at this time to lead a more settled life, and consequently he was enabled to take meat and vegetables at least twice daily, and on October 30th, 1877, two or three months afterwards, he presented himself without a trace of eruption excepting some staining and faint pitting here and there. During the time he remained under observation the man had no itching whatever and no other uncomfortable sensation about the skin of any kind, which was a remarkable character of the eruption. Nor could $I$ detect any sign of syphilis about him.
Remarks.-Hebra describes this disease as occurring in cachectic persons and especially scrofulous subjects, and also in patients recovering from scurvy; and in the latter case as having a purplish hæmorrhagic border around the separate spots; the eruption resembles a syphilitic rash, but leads to no specific ulcers. My case fulfils exactly the conditions pointed out by Hebra as belonging to the disease following in the wake of scurvy.

Iodide of potassium may in some cases excite an acneiform rash, more or less generally about the body, especially the limbs, but it is acne of a bright-red hue and active progress; it subsides on the omission of the drug, and is not necessarily connected with cachexia.

I record this case of acne cachecticorum for the special purpose of contrasting it with pruriginous hydroa. The latter is essentially a pruritic disease, perhaps the most pruritic disease there is, made up of paroxysmal attacks of eruption composed at the outset of small bullæ, which may become somewhat purulent, and resemble acne spots, but which soon subside into pruritic papulations, and torment the patient for weeks and months. Acne cachecticorum is never pruritic; it is as indolent and sluggish a disease as can well be imagined. It is not paroxysmal in its attack ; it is associated with definite cachectic conditions.

The case of disease recorded in a recent volume of the Medico-Chirurgical Transactions as one of acne cachecticorum is not that disease at all. It was an instance of pruriginous hydroa, and was under my care and observation some time. It was a very pruritic disease, made up of paroxysmal outbreaks of small bullæ and quasi-herpetic patches, not acneiform in any sense, and essentially neurotic in origin.

\section{HYDROCELE OF THE FEMORAL CANAL.} BY SAMUEL OSBORN, F.R.C.S.

HYDROCELE occurring in the female subject is always rare, but that of the femoral canal is less frequent than that of the canal of Nuck. The following case I believe to have been hydrocele of the femoral canal, or, in other words, a process of peritoneum projected from the general peritoneal cavity, and not a hydrocele of a femoral sac, where the communication with the peritoneum is shut off by either intestine or omentum becoming adherent to the mouth of the sac. My reasons for so thinking are that after the withdrawal of the fluid no impulse was obtainable on the patient's coughing, nor was there on manipulation any sensation of there being a rupture in the femoral canal.

Caroline $\mathrm{S}-$, aged fifty-two, single, first noticed a swelling in her right groin eighteen months ago. About the same time she had been troubled with much sickness, and was attending as an out-patient at Middlesex Hospital, but is quite sure that the swelling did not commence during or immediately after a fit of retching. When first noticed she states that it was the size of her little finger, rather elongated, and like a swollen vein. For fourteen months she had no pain or trouble of any sort from the tumour, but four months ago it began to get much larger-in fact, twice the size it was before, and very hard. She then saw a doctor, who said she was ruptured, and she thinks he reduced a portion of the swelling, as it again went back to its original size. About fourteen days ago it again became larger, causing her much pain. This time she fancies she reduced the swelling somewhat herself. She had never worn a truss.

She first came under my notice at the Surgical Appliance Society, to which she had applied for a femoral truss, believing herself to have an irreducible hernia. On examination there was found to be a tumour over the saphenous opening about the size of a bantam's egg, smooth, fluctuating, and transparent by transmitted light, with some hard nodules below and at the inner side. When first seen taxis failed to make any alteration in its size; on a subsequent occasion, however, taxis succeeded in partially reducing the swelling, but the same evening it was again as large as at first.

Nov. 8th.-Cyst tapped and completely emptied ; about nine drachms of clear, pale-yellow serous fluid being withdrawn, identical in all respects with the fluid obtained from a hydrocele of the inguinal canal. The hard nodules more 